\title{
Pengaruh Doping Nikel dan Suhu Sinter pada Pembuatan Kawat Superkonduktor Magnesium Diborida
}

\author{
Satrio Herbirowo ${ }^{1 *}$, M. Nur Hanafi ${ }^{2}$, Agung Imaduddin ${ }^{1}$, Edy Priyanto Utomo ${ }^{1}$, \\ Hendrik $^{1}$, Adhitya Trenggono ${ }^{2}$, Erlina Yustanti ${ }^{2}$ \\ ${ }^{1}$ Pusat Penelitian Metalurgi dan Material - LIPI Gedung 470 Kawasan Puspiptek - Serpong, Tangerang \\ Selatan, Banten 15314, Indonesia \\ ${ }^{2}$ Teknik Metalurgi, Fakultas Teknik, Universitas Sultan Ageng Tirtayasa \\ Jl. Jenderal Sudirman Km 3 Cilegon, Banten 42435, Indonesia \\ *satr006@lipi.go.id
}

\begin{abstract}
Improvement of $\mathrm{MgB}_{2}$ superconducting properties through the addition of doping has been done. Even so, the manufacture of $\mathrm{MgB}_{2}$ superconducting wire has not been optimally produced due to porosity formed from the $\mathrm{MgB}_{2}$ layer structure. The purpose of this study was to analyze the effect of adding nickel doping to the value of crystallinity and optimum density and temperature in the synthesis of $\mathrm{MgB}_{2}$-based superconductor wire. The process variables in the sample used are $\mathrm{Ni}$ doped weight percent variation and sintering temperature. Characterizations used include Xray Diffraction (XRD), Scanning Electron Micoscope-Energy Dispersive Spectroscopy (SEM-EDS), and Cryogenic Magnets. The manufacturing process uses powder metallurgy with in-situ powder in tube method and wire rolling manufacturing. Rolling is done by reducing the diameter of $6 \mathrm{~mm}$ to $4 \mathrm{~mm}$, and the initial length of $10 \mathrm{~cm}$ to \pm $26 \mathrm{~cm}$. XRD results showed that the nickel doped sample produced $\mathrm{MgB}_{2}$ primary phase and $\mathrm{MgNi}$ 2.5B2 secondary phase and some impurities $(\mathrm{MgO}$ and $\mathrm{Mg}$ ) with crystallite size increased more than $\mathrm{MgB}_{2}$ without doping. From the SEM image, the sample appears to show a decrease in the amount of porosity. The sintered $750{ }^{\circ} \mathrm{C}$ sample is the optimal temperature in synthesizing nickel doped $\mathrm{MgB}_{2}$ superconductors because it has the highest on Tc of 42.53 $\mathrm{K}$ and the lowest porosity in nickel doping of $20 \mathrm{wt}$. \% is of $13.5 \%$ of porosity.
\end{abstract}

Keywords: Superconductor, Magnesium diboride, nickel doping, porosity.

\section{ABSTRAK}

Peningkatan sifat superkonduktor $\mathrm{MgB}_{2}$ melalui penambahan doping telah banyak dilakukan. Meskipun begitu, pembuatan kawat superkonduktor $\mathrm{MgB}_{2}$ belum secara optimal dihasilkan akibat porositas yang terbentuk dari struktur lapis $\mathrm{MgB}_{2}$. Tujuan penelitian ini adalah untuk menganalisis efek penambahan doping nikel terhadap nilai kristalinitas dan kepadatan serta temperatur optimum dalam sintesis kawat superkonduktor berbasis $\mathrm{MgB}_{2}$. Variabel proses pada sampel yang digunakan yaitu variasi persen berat doping Nikel dan temperatur sintering. Karakterisasi yang digunakan meliputi Xray Diffraction (XRD), Scanning Electron Micoscope-Energy Dispersive Spectroscopy (SEM-EDS), dan Cryogenic Magnet. Pembuatannya menggunakan proses metalurgi serbuk dengan metode powder in tube secara in-situ dan manufaktur pengerolan kawat. Pengerolan dilakukan reduksi ukuran diameter 6 $\mathrm{mm}$ menjadi $4 \mathrm{~mm}$, serta panjang awalnya $10 \mathrm{~cm}$ menjadi $\pm 26 \mathrm{~cm}$. Dari hasil XRD menunjukkan bahwa sampel dengan doping nikel menghasilkan fasa primer $\mathrm{MgB}_{2}$ dan fasa sekunder $\mathrm{MgNi}_{2.5} \mathrm{~B}_{2}$ serta beberapa pengotor $(\mathrm{MgO}$ dan $\mathrm{Mg}$ ) dengan ukuran kristalit lebih meningkat dibandingkan $\mathrm{MgB}_{2}$ tanpa doping. Dari gambar SEM, sampel tampak menunjukkan penurunan jumlah porositasnya. Sampel yang disinter $750^{\circ} \mathrm{C}$ merupakan temperatur optimal dalam mensintesis superkonduktor $\mathrm{MgB}_{2}$ yang didoping nikel karena memiliki $\mathrm{Tc}$ onset 
tertinggi sebesar $42,53 \mathrm{~K}$ dan porositas terendah pada pendopingan nikel sebesar 20 persen

berat yaitu sebesar $13,5 \%$ porositas.

Kata kunci: superkonduktor, magnesium diborida, doping nikel, porositas.

\section{PENDAHULUAN}

Magnesium diboride $\left(\mathrm{MgB}_{2}\right)$, yang baru ditemukan pada tahun 2001 oleh Nagamatsu dkk, merupakan material superkonduktor $\mathrm{MgB}_{2}$ dengan temperatur kritis $(\mathrm{Tc}=39 \mathrm{~K})$ dan bahan berbasis logam yang mempunyai Tc tertinggi sehingga dapat digunakan pada suhu operasional 20-25 K dalam kondisi cryocooler yang lebih murah. Penelitian dan pengembangan material $\mathrm{MgB}_{2}$ yang dilakukan diharapkan dapat menggantikan superkonduktor suhu rendah seperti $\mathrm{NbTi}$ dan $\mathrm{Nb}_{3} \mathrm{Sn}$ karena selain mempunyai nilai temperatur kritis yang lebih tinggi, superkonduktor $\mathrm{MgB}_{2}$ berbahan dasar $\mathrm{Mg}$ merupakan sumber daya yang melimpah dan lebih murah dibandingkan dengan $\mathrm{NbTi}$ maupun $\mathrm{Nb}_{3} \mathrm{Sn}$ [1]. Pada penelitian yang telah dilakukan oleh Erhan aksu, mengenai pengaruh variasi temperatur sintering, mikrostruktur heksagonal fasa $\mathrm{MgB}_{2}$ meningkat seiring dengan meningkatnya temperatur sintering dari 750 sampai $950^{\circ} \mathrm{C}^{[3]}$ dan penelitian oleh Qian Zhao, dkk, di dapat hasil bahwa penambahan doping nikel pada bahan magnesium diborida dapat meningkatkan rapat arus kritis (Jc), selain itu Ni dapat memperbaiki karakter dari kritalinitas dan konektivitas antar partikel serta dapat meningkatkan kepadatan sehingga mampu menurunkan porositas dan menurunkan suhu sintering dalam mensintesis superkonduktor $\mathrm{MgB}_{2}{ }^{[4]}$

Dalam pengaplikasian teknologinya superkonduktor biasa dibuat dalam bentuk kawat. Proses pembuatan kawat pada penelitian ini menggunakan metode powder in tube secara in situ dimana memiliki kelebihan dapat dipanaskan pada kondisi atmosferik sehingga tidak perlu dialiri gas argon untuk kondisi inert sehingga lebih sederhana dan lebih murah. Pada metode ini, serbuk Mg dan serbuk B dengan komposisi stoikiometri yang diinginkan dimasukkan kedalam tabung logam seperti $\mathrm{Ni}, \mathrm{Cu}$, atau stainless steel (SS). Pada penelitian ini menggunakan tabung terbuat dari baja SS 304, yang jauh lebih murah dibandingkan tabung logam $\mathrm{Ni}$ dan $\mathrm{Cu}$ dan dari hasil karakterisasi mempelihatkan dengan penggunaan tabung berbahan stainless steel di dapat fasa $\mathrm{MgB}_{2}$ baik terbentuk karena serbuk tidak bereaksi dengan tabungnya ${ }^{[2]}$.

Selanjutnya kami akan mencoba memvariasikan temperatur sintering dan persen berat doping nikel pada pembuatan kawat superkonduktor sehingga diharapkan mendapat parameter temperatur optimum dalam sintesis kawat superkonduktor berbasis $\mathrm{SS} / \mathrm{MgB}_{2}$ dan dievaluasi efek penambahan doping nikel terhadap nilai kristalinitas dan kepadatan mikrostruktur kawat $\mathrm{MgB}_{2}$.

\section{METODE}

Bahan yang digunakan adalah serbuk Magnesium (kemurnian 98\%, Sigma aldrich) dengan ukuran 100 mesh, serbuk Boron (kemurnian 95\%, merek KGaA, Germany), serbuk nikel (kemurnian 99\%, merek KGaA, Germany) dengan ukuran $10 \mu \mathrm{m}$ dan tabung stainless steel tipe 304. Proses diawali dengan preparasi tabung SS 304 dengan pemotongan tabung masing-masing dengan panjang $10 \mathrm{~cm}$ lalu dilanjutkan proses annealing untuk meningkatkan formabilitas tabung tersebut kemudian dilakukan pembubutan dan pembersihan dan terakhir ditutup dengan rod penutup. 
Selanjutnya serbuk ditimbang dengan komposisi yang telah ditentukan sesuai perhitungan stoikiometri. Adapun variasi doping yang digunakan yaitu serbuk $\mathrm{Ni}$ dengan 3 variasi komposisi berat masing-masing dopan sebesar $0 ; 10 \%$, dan $20 \%$ berat. Dalam perhitungan berat dalam gram disesuaikan dengan volume tabung.

Campuran serbuk kemudian digerus menggunakan mortar agate selama 1 jam hingga menjadi homogen. Lalu dilanjutkan proses memasukkan serbuk kedalam tabung SS 304 dan ditutup. Sampel kemudian dilanjutkan ke proses pembuatan kawat menggunakan alat wire rolling. Proses ini berfungsi untuk merubah tabung SS 304 yang berisi serbuk untuk dijadikan kawat superkonduktor sehingga mereduksi ukuran tabung tersebut dengan gaya tekan putar sebelum dilakukan proses pemanasan serta membuat serbuk di dalam tabung menjadi lebih padat ${ }^{[5]}$.

Kawat hasil proses rolling disinter guna membentuk ikatan antar atom, densifikasi, mengeliminasi porositas dan mesintesis serbuk menjadi superkonduktor $\mathrm{MgB}_{2}$. Proses sintering dilakukan pada 3 variasi temperatur, yaitu 750,850 dan $950^{\circ} \mathrm{C}$ lalu ditahan selama 1 jam pada masing-masing temperatur, kemudian dibiarkan dingin didalam furnace. Hasil dari sintering kemudian dilakukan karakterisasi menggunakan X-ray Diffractometer (XRD), Scanning Electron Microscopy/Energy Dispersive Spectroscopy SEM/EDS Mapping dan Cryogenic magnet guna mengetahui fasa-fasa yang muncul melalui pola difraksi, morfologi struktur mikro yang terbentuk dan sifat superkonduktivitas yang ditandai dengan mengukur resistivitas dari material tersebut.

\section{HASIL DAN PEMBAHASAN}

Penelitian ini merupakan proses manufaktur kawat superkonduktor yang berbahan dasar $\mathrm{MgB}_{2}$ dengan beberapa variasi yaitu variasi doping dan variasi suhu sinter yang ditunjukkan pada Gambar 1. Kawat dibuat dengan metode powder in tube secara in situ yang mana dilanjutkan wire rolling dimana terjadi perubahan dimensi yang awalnya sebelum dilakukan proses rolling tabung tersebut berdiameter $6 \mathrm{~mm}$ dengan panjang 10 $\mathrm{cm}$, namun setelah dilakukan proses rolling dimensinya berubah keukuran diameter $4 \mathrm{~mm}$ dengan panjang sekitar $26 \mathrm{~cm}$, bervariasi tergantung dari proses penekukan untuk menutup pada bagian ujung kawat, yang tidak sama antara satu tabung dengan tabung lainnya.

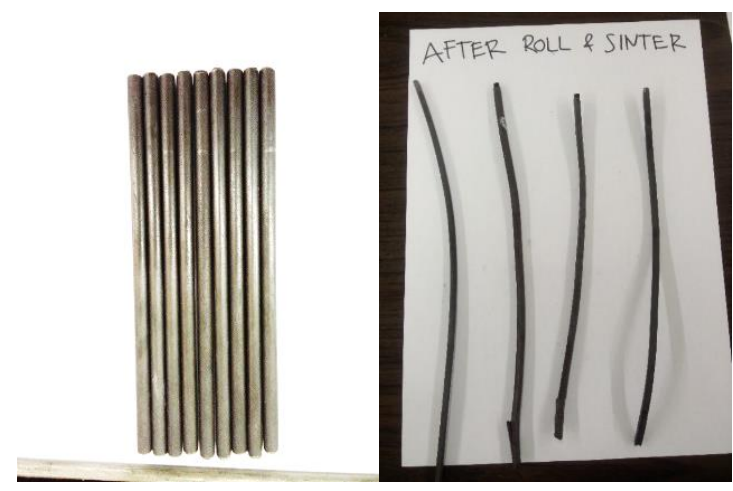

Gambar 1. Tabung SS 304 sebelum proses dan kawat setelah proses rolling dan sintering

\section{Pengaruh penambahan doping nikel pada pembetukan fasa dan kristalinitas}

Pengaruh penambahan doping nikel terhadap fasa yang terbentuk dapat dilihat dari Gambar 2 hasil analisis XRD dimana dibaca dari pola difraksi yang muncul dari ketiga variasi \% doping pada ketiga temperatur sintering yaitu $750^{\circ} \mathrm{C}, 850^{\circ} \mathrm{C}$, dan $950^{\circ} \mathrm{C}$. 


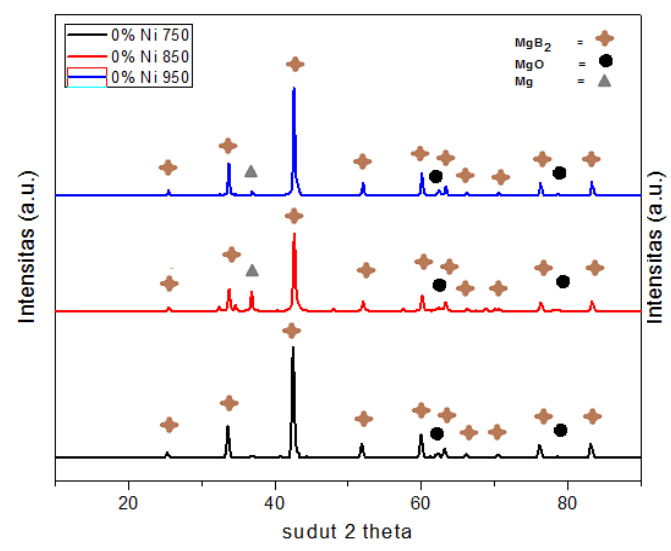

(a)

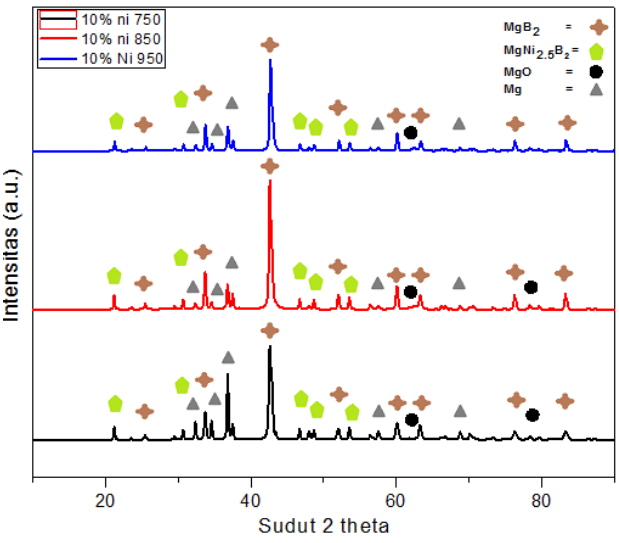

(b)

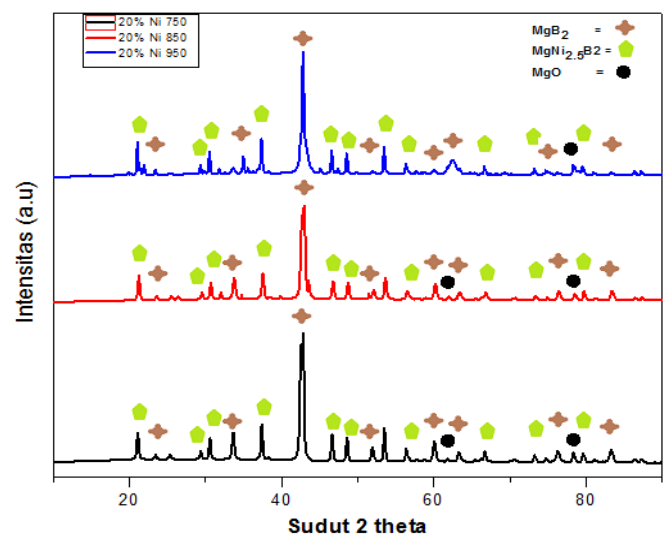

(c)

Gambar 2. Pola difraksi XRD dengan variasi doping Ni (a)0\%, (b)10\%, (c)20\% berat pada 3 temperatur sintering

Dari ketiga variasi \% doping Ni pada setiap temperatur dari pola difraksi pada Gambar 2, didapat fasa $\mathrm{MgB}_{2}$ sebagai fasa primer atau fasa utama dengan database no referensi ICSD 98-010-8064 yang terbentuk dimana membuktikan bahwa serbuk $\mathrm{Mg}$ dan B berhasil disintesis dan bereaksi dengan baik. Selanjutnya pada pola difraksi dengan penambahan doping $\mathrm{Ni}$ dengan variasi doping $10 \%$ dan $20 \% \mathrm{Ni}$ didapat fasa sekunder $\mathrm{MgNi}_{2.5} \mathrm{~B}_{2}$ dengan database referensi 98-010-0111dimana fasa ini merupakan reaksi antara Ni dengan $\mathrm{Mg}$ dan $\mathrm{B}$ dan dapat diperoleh di atas $600^{\circ} \mathrm{C}$. Selanjutnya didapat juga fasa $\mathrm{MgO}$ dan unsur $\mathrm{Mg}$ merupakan pengotornya. Fasa $\mathrm{MgO}$ dengan database referensi ICSD 98-0088058 bereaksi dengan $\mathrm{Mg}$ sehingga menjadi $\mathrm{MgO}$ dan bisa terjadi juga akibat proses solid state serbuk Mg didalam tabung yang belum maksimal sehingga berikatan dengan oksigen yang terperangkap dalam tabung pada saat proses berlangsung. Unsur Mg sendiri akibat masih adanya $\mathrm{Mg}$ yang belum meleleh sempurna pada saat proses sintering di dalam tabung SS 304 tersebut. Dari ketiga variasi tersebut terlihat semakin besar \% doping nikel yang ditambah maka fasa sekunder $\mathrm{MgNi}_{2.5} \mathrm{~B}_{2}$ juga semakin banyak terbentuk dan tidak terdapat pada variasi $0 \% \mathrm{Ni}$ atau tanpa doping. Hal ini menyatakan fasa ini muncul akibat penambahan dari doping nikel.

Dari analisis data XRD juga dilihat pengaruh doping Ni terhadap kristanilitas yang mana dapat diketahui dengan menghitung ukuran kristalit atau crystallite size dengan menggunakan 2 metode yaitu dapat menggunakan software HighScore Plus (HSP) dan perhitungan manual menggunakan Debye Scherrer equation. 


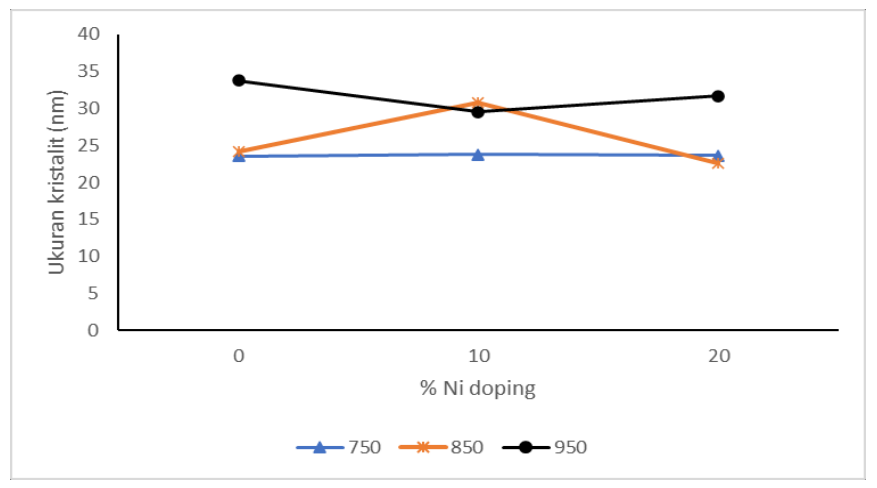

Gambar 3. Grafik Ukuran kristalit (Scherrer equation) Terhadap Temperatur Sintering Dan \% Doping Ni

hasil perhitungan menyatakan bahwa pada sampel dengan temperatur sintering $750^{\circ} \mathrm{C}$ dengan penambahan doping $\mathrm{Ni}$ pada kedua metode cenderung meningkatkan ukuran kristalit, dan yang memiliki ukuran kristalit terbesar yaitu dengan penambahan doping $10 \% \mathrm{Ni}$. Ukuran kristalit terbesar juga terdapat dengan penambahan $10 \% \mathrm{Ni}$, sedangkan pada temperatur $950^{\circ} \mathrm{C}$ sama dengan nilai FWHM yaitu berkebalikan dengan dua temperatur lainnya, dimana penambahan doping Ni malah menurunkan sedikit ukuran kristalitnya dan memiliki ukuran kristalit terbaik pada sampel $0 \% \mathrm{Ni}$. Hal ini bisa terjadi karena temperatur sintering yang terlalu tinggi menyebabkan fasa $\mathrm{MgB}_{2}$ terdekomposisi dan muncul banyak fasa pengotor seperti $\mathrm{MgO}^{[6]}$

\section{Pengaruh penambahan doping nikel dan temperatur sintering pada morfologi dan struktur mikro serta porositas}

Karakterisasi dengan menggunakan SEM-EDS mapping dapat dilihat pengaruh doping $\mathrm{Ni}$ dan variasi temperatur sintering terhadap morfologi permukaan dan struktur mikro kawat superkonduktor $\mathrm{MgB}_{2}$ seperti telihat pada Gambar 4 dan Gambar 5
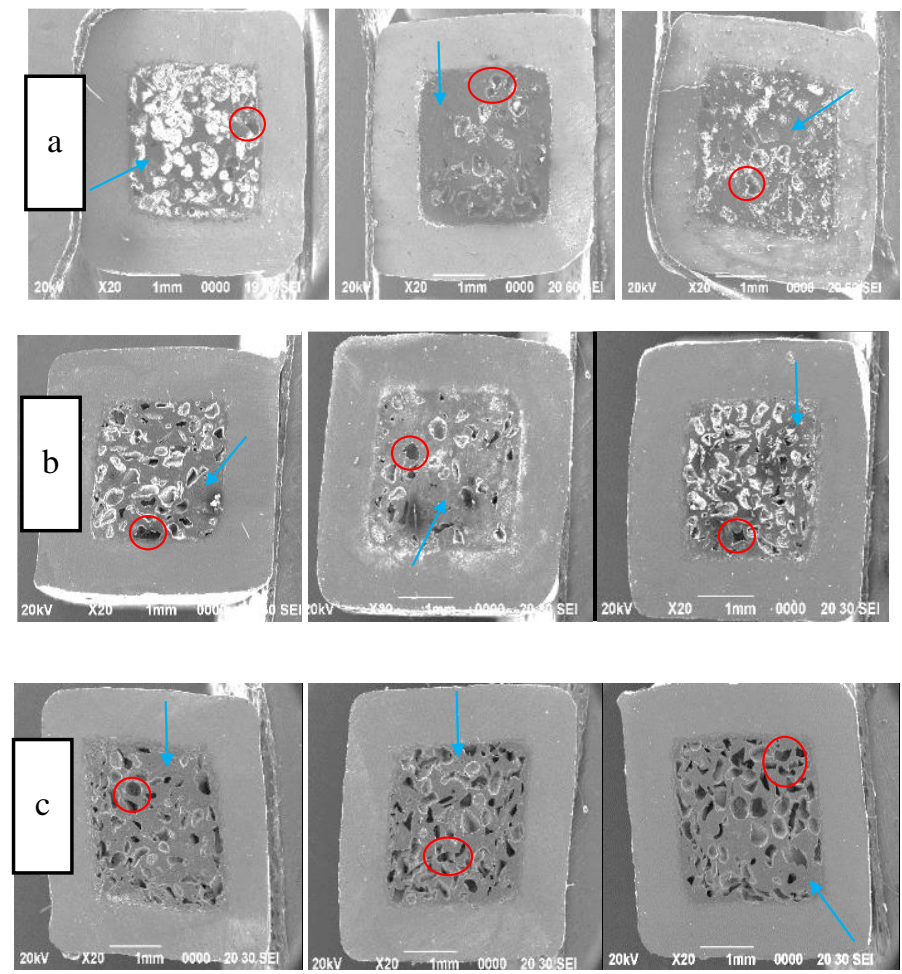

Gambar 4. Hasil SEM penampang melintang kawat pembesaran 20X dengan doping Ni (a) 0\%, (b) 10\%, dan (c) $20 \%$ 
Gambar 4 merupakan hasil pengamatan SEM secara makro penampang melintang kawat pada temperatur sintering $750^{\circ} \mathrm{C}, 850^{\circ} \mathrm{C}$ dan $950^{\circ} \mathrm{C}$, dimana dari gambar terlihat masih terdapat porositas. Hal ini berarti kurang terbentuknya konektifitas antar butir yang mengakibatkan banyaknya lubang-lubang yang terbentuk. Porositas ini terjadi karena reduksi volume dari reaksi $\mathrm{Mg}+2 \mathrm{~B}$. Proses sintering yang diberikan pada kawat mengakibatkan $\mathrm{Mg}$ berubah fasa menjadi liquid dan menutupi Boron. Hal ini mengakibatkan terjadinya reduksi volume intrinsik dan meninggalkan ruang yang menyebabkan terjadinya porositas ${ }^{[7]}$.

Terlihat juga seluruh bahan stainless steel dengan ketebalan dinding dibawah $1 \mathrm{~mm}$ menyatu dengan bahan serbuk $\mathrm{MgB}_{2}$ tanpa ada retakan. Hal tersebut menunjukkan kawat ini berupa kawat monofilament. Warna hitam gelap yang dan tampak bolong yang dilingkari merupakan contoh porositas yang terjadi sedangkan warna abu-abu selain yang bewarna gelap yang ditandai garis biru merupakan fasa $\mathrm{MgB}_{2}$ yang terbentuk ${ }^{[8]}$. Dari pengaruh temperatur terlihat semakin tinggi temperatur maka semakin banyak poros yang terbentuk. Namun dari pengaruh doping Ni pada pembesaran $20 \mathrm{X}$ ini terlihat kepadatan meningkat dengan penambahan doping $\mathrm{Ni} 10 \%$ berat dibandingkan pada kawat tanpa doping, namun pada penambahan doping $\mathrm{Ni} 20 \%$ kepadatan terlihat menurun karena porositas semakin jelas terlihat.

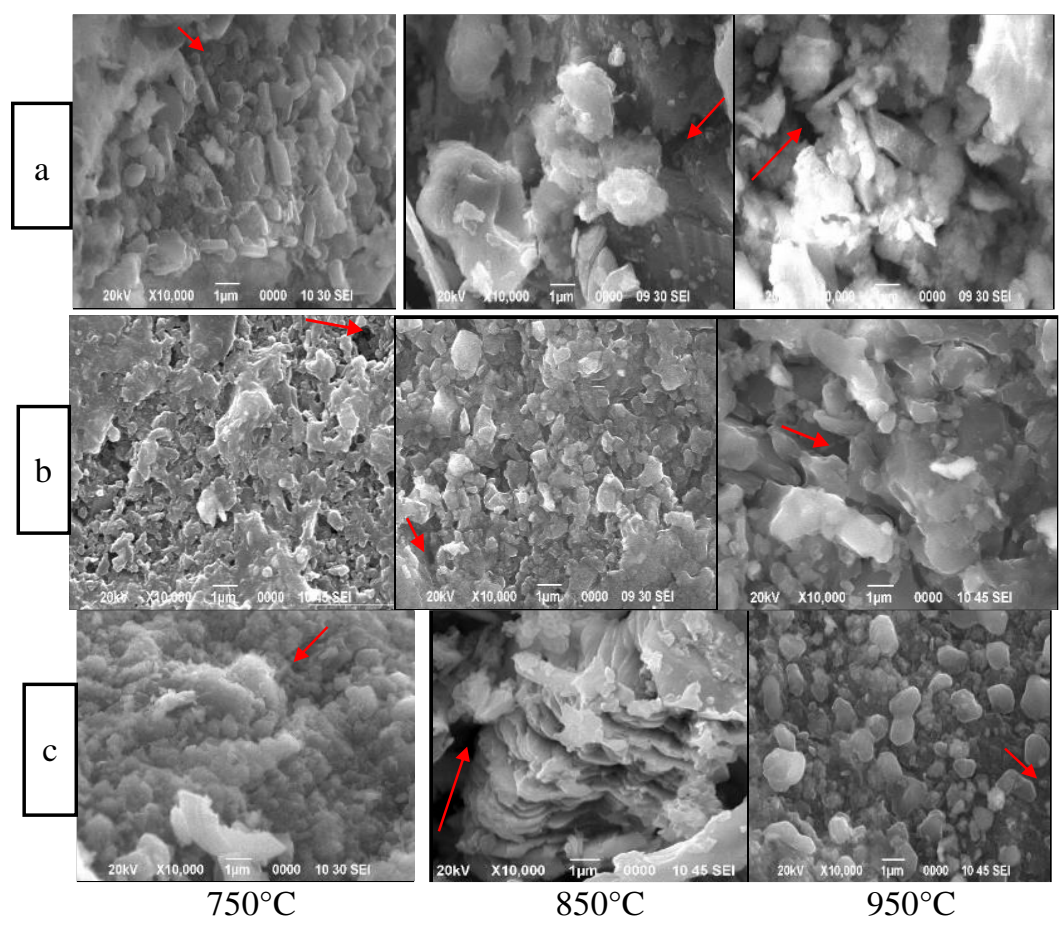

Gambar 5. Hasil SEM kawat $\mathrm{MgB}_{2}$ pembesaran $10000 \mathrm{X}$ dengan variasi doping $\mathrm{Ni}$ (a)0\%, (b)10\%, dan (c)20\%

Gambar 5 merupakan hasil pengamatan SEM secara mikro dari morfologi tiap sampel membentuk granul-granul dengan strukur kristal yang heksagonal yang merupakan karakteristik $\mathrm{MgB}_{2}$. Dari gambar juga terlihat sedikit void yang ditandai garis merah, serta Mg dan B berdifusi merata terlihat bahwa agregat mikro sudah saling mengikat, namun pada beberapa sampel masih teraglomerasi dibeberapa bagian. Berdasarkan variasi doping $\mathrm{Ni}$, pada pembesaran $10000 \mathrm{X}$ dimana seamakin besar \% doping nikel yg diberikan maka kepadatan terlihat lebih meningkat serta meningkatkan batas butir dengan semakin kecil 
ukuran partikelnya yang mengacu pada penelitian sebelumnya menggunakan doping $\mathrm{NiO}^{[9]}$ dimana celah antar unsur terlihat lebih kecil dan sedikit. Untuk pengaruh suhu terhadap morfologi terlihat jelas bahwa semakin tinggi suhu sinter maka bentuk partikel atau butir semakin jelas terlihat dan semakin kristalin antar batas butirnya.

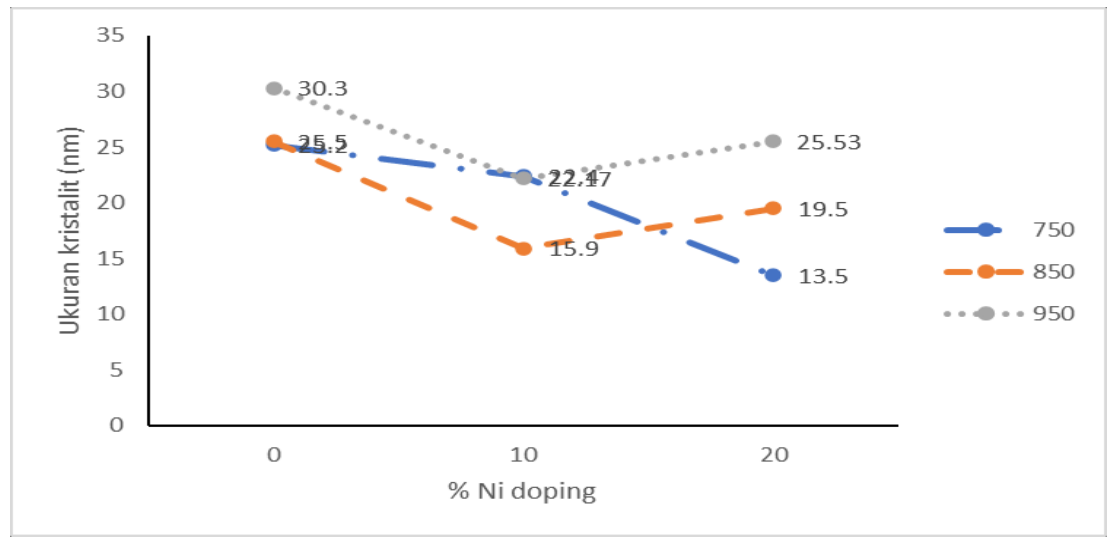

Gambar 6. Grafik \% Porositas Dengan Variasi \% Doping Ni pada Setiap Temperatur

Gambar 6 merupakan data perhitungan persen porositas pada kawat superkonduktor $\mathrm{MgB}_{2}$ yang dihitung menggunakan sofware Image J. Dari data tersebut terlihat bahwa pada sampel dengan variasi doping $0 \% \mathrm{Ni}$ atau tanpa doping, sedangkan pada variasi doping $10 \% \mathrm{Ni}$ justru porositas terbesar pada temperatur $750^{\circ} \mathrm{C}$. Pada doping $20 \% \mathrm{Ni}$ pada temperatur $950^{\circ} \mathrm{C}$. Hal ini karena pada temperatur $950^{\circ} \mathrm{C}$ mendekati temperatur uap dari $\mathrm{Mg}$ sehingga banyak $\mathrm{Mg}$ yang menguap dan menyebabkan porositas ${ }^{[10]}$. Namun jika dilihat dari pengaruh penambahan doping $\mathrm{Ni}$ pada setiap temperatur sintering, dengan temperatur $750^{\circ} \mathrm{C}$ semakin banyak \% nikel maka porositas semakin menurun, adapun pada temperatur $850^{\circ} \mathrm{C}$ juga menurunkan porositas, tetapi dengan penambahan $20 \% \mathrm{Ni}$ lebih tinggi daripada $10 \% \mathrm{Ni}$, sedangkan pada temperatur $950^{\circ} \mathrm{C}$ sama halnya dengan $850^{\circ} \mathrm{C}$, porositas juga menurun dengan penambahan doping $\mathrm{Ni}$, tetapi penambahan $20 \% \mathrm{Ni}$ lebih tinggi daripada $10 \%$ Ni. Dari seluruh temperatur terlihat bahwa penambahan doping nikel cenderung menurukan porositas. Hal ini bisa terjadi karena nikel dapat memperbaiki konektivitas antar butir sehingga meningkatkan kepadatan dan menurunkan porositas.
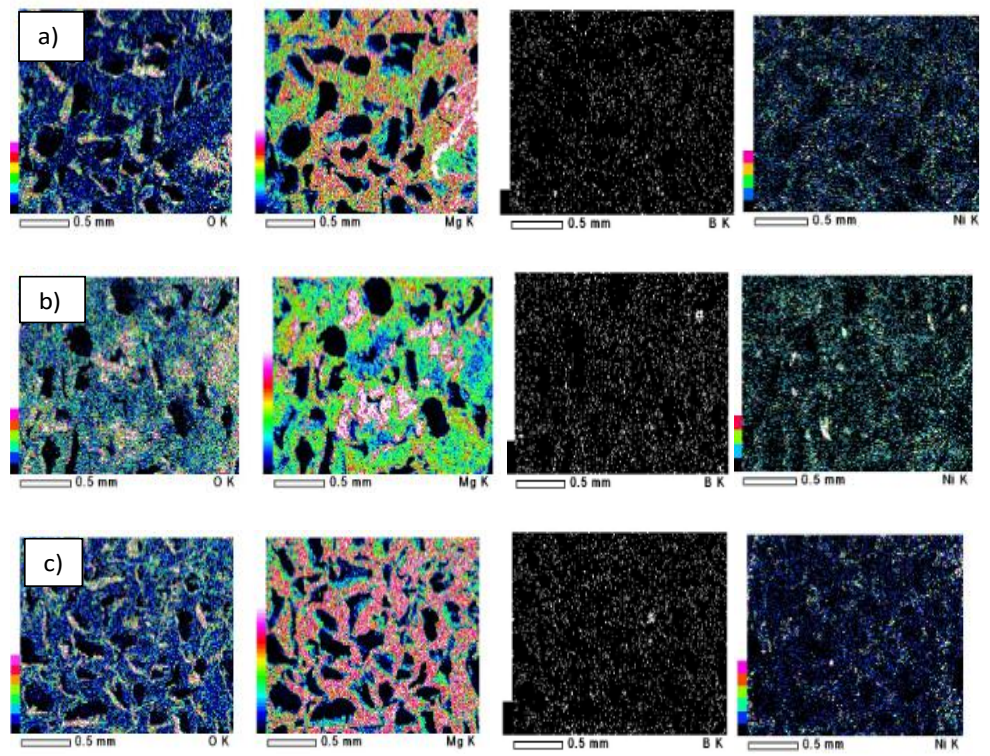

Gambar 7. Grafik \% Porositas Dengan Variasi \% Doping Ni pada Setiap Temperatur 
Gambar 7 merupakan hasil SEM-EDS Mapping dimana terlihat persebaran tiap unsur yang terdapat pada kawat. Dari gambar terlihat bahwa setiap unsur baik $\mathrm{Mg}, \mathrm{B}$ dan Ni serta didapat unsur pengotor $\mathrm{O}$ terdispersi atau tersebar merata disetiap bagian tabung terkecuali pada bagian terkena porositasnya. Hal ini menandakan bahwa serbuk berhasil berdifusi dan bereaksi dengan baik.

\section{Pengaruh penambahan doping nikel terhadap resisitivitas pada superkonduktor $\mathrm{MgB}_{2}$}

Pengukuran resistivitas bertujuan melihat sifat superkonduktivitas dari material tersebut yang ditunjukkan dengan temperatur kritis (Tc) dari material tersebut.

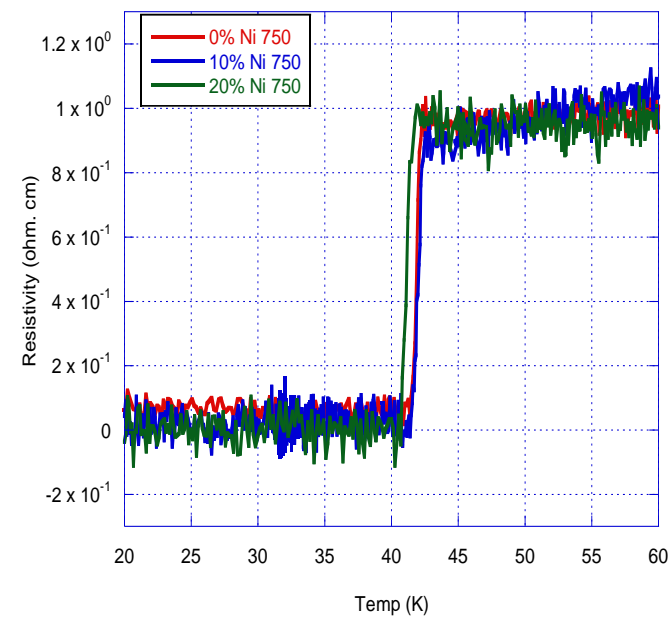

(a)

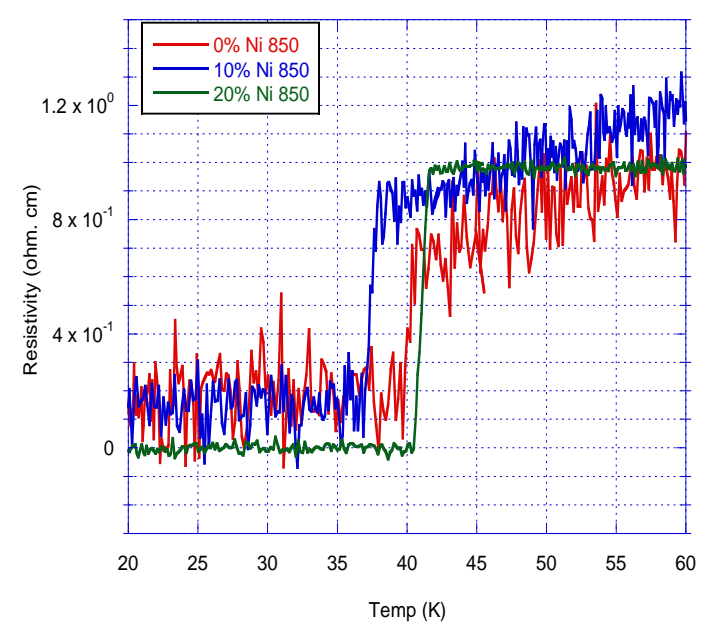

(b)

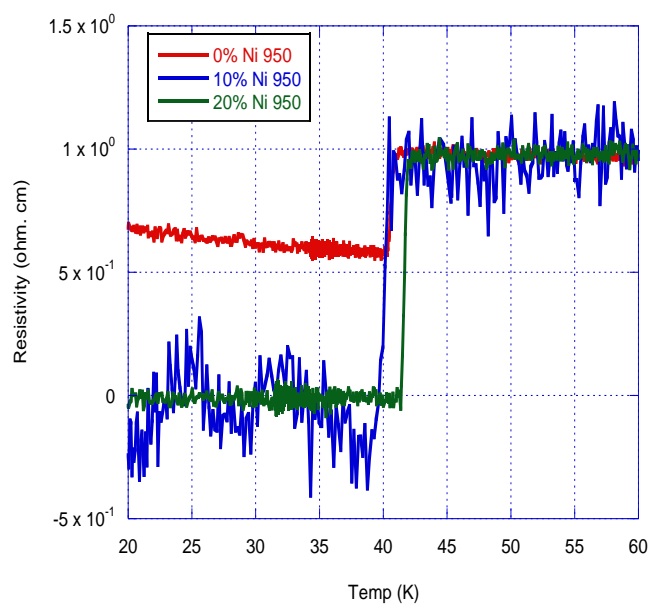

(c)

Gambar 8. Grafik Resistivitas Kawat Superkonduktor MgB2 Pada T= 750 (a), 850 (b) dan $950^{\circ} \mathrm{C}$ (c) dengan variasi doping Ni 0, 10 dan 20\%wt

Dari grafik pada temperatur sintering $750^{\circ} \mathrm{C}$ bahwa temperatur kritis tertinggi didapat pada sampel penambahan doping Ni $10 \%$ berat. Adapun pada temperatur sintering $850^{\circ} \mathrm{C}$ temperatur kritis tertinggi didapat pada sampel dengan penambahan doping $\mathrm{Ni}$ sebanyak $20 \%$ berat. Sedangkan, pada temperatur sintering yang tertinggi yaitu $950^{\circ} \mathrm{C}$ didapat temperatur kritis tertinggi sama dengan tempertur $850^{\circ} \mathrm{C}$, yaitu dengan sampel dengan variasi doping Ni sebanyak $20 \%$ berat. Dari ketiga temperatur, secara umum dapat 
disimpulkan bahwa dengan doping Ni cenderung meningkatkan temperatur kritisnya. Hal ini bisa terjadi karena doping Ni dapat meperbaiki kristalinitas dan konektivitas antar butir dari superkonduktor $\mathrm{MgB}_{2}{ }^{[11]}$ maka arus listrik yang dialirkan suhu kritis (Tc) dari material tersebut.

\section{KESIMPULAN}

Kawat superkonduktor $\mathrm{MgB}_{2}$ berhasil dibuat dengan proses metalurgi serbuk menggunakan metode powder in tube secara in-situ dan manufaktur pengerolan kawat dibuktikan dengan adanya sifat superkonduktifitas. Hasil pengujian XRD dari superkonduktor $\mathrm{MgB}_{2}$ dan didoping Ni didapatkan fasa primer $\mathrm{MgB}_{2}$ dan fasa sekunder $\mathrm{MgNi}_{2.5} \mathrm{~B}_{2}$, serta senyawa $\mathrm{MgO}$ dan unsur $\mathrm{Mg}$ sebagai fasa pengotornya. Penambahan doping Ni cenderung meningkatkan kristalinitas dan ukuran kristalit, dengan penambahan terbaik yaitu $10 \% \mathrm{Ni}$.

Partikel Mg-B-Ni terdistribusi merata dalam kawat superkonduktor dan pengaruh penambahan doping $\mathrm{Ni}$ dapat menurunkan porositas, dan porositas terendah pada pendopingan nikel $20 \%$ berat yaitu sebesar $13,5 \%$. Temperatur sintering $750^{\circ} \mathrm{C}$ merupakan temperatur optimal dalam mensintesis superkonduktor $\mathrm{MgB}_{2}$ yang didoping nikel karena memiliki Tc onset tertinggi sebesar 42,53 K yang secara morfologi suhu sinter juga mempengaruhi bentuk maupun batas butir.

\section{UCAPAN TERIMAKASIH}

Penulis mengucapkan terima kasih kepada Pusat Penelitian Metalurgi dan Material - LIPI yang telah mendanai serta memberikan fasilitas alat proses dan pengujian superkondiktifitas melalui kegiatan DIPA Tematik tahun 2018. Ucapan terimakasih juga diberikan kepada para peneliti dan teknisi tim superkonduktor serta kerjasama penelitian dengan Universitas Sultan Ageng Tirtayasa.

\section{DAFTAR PUSTAKA}

1 Nagamatsu, J. (2000), Superconductivity at $49 \mathrm{~K}$ in copper doping magnesium diboride, Nature, Vol. 410, No. March, hal. 1-3.

2 Varghese, N. K. Vinod, R. G. Abhilash Kumar, U. Syamaprasad, and A. Sundaresan, (2007), Influence of reactivity of sheath materials with $\mathrm{Mg} / \mathrm{B}$ on superconducting properties of $\mathrm{MgB}_{2}$, J. Appl. Phys., Vol. 102, No. 4, hal. 0-4.

3 Aksu, E. (2013), Study of $\mathrm{MgB}_{2}$ phase formation by using XRD, SEM, thermal and magnetic measurements, J. Alloys Compd., Vol. 552, hal. 376-381.

4 Zhao, Q., Y. Liu, and Q. Cai, (2012), Influence of Ni addition on the process of phase formation in MgB 2 bulk, Appl. Phys. A Mater. Sci. Process., Vol. 107, No. 4, hal. 877-883.

5 Herbirowo, S., Sofyan, N., Imaduddin, A., (2017), Properties of carbon nanotubesdoped $\mathrm{Fe}$-sheath $\mathrm{MgB}_{2}$ for superconducting wires, AIP Conf. Proc., Vol. 1826.

6 Cai, Q., Z. Ma, Q. Zhao, and Y. Liu, (2011) Observation of flux jump in (MgB 2) $0.96 \mathrm{Ni} 0.04$ superconductor doped with milled Ni powders, J. Supercond. Nov. Magn., Vol. 24, No. 6, hal. 2013-2017. 
7 Vinod, K., N. Varghese, R. G. A. Kumar, U. Syamaprasad, and S. B. Roy, (2008), Influence of $\mathrm{Mg}$ particle size on the reactivity and superconducting properties of in situ $\mathrm{MgB}_{2}$, J. Alloys Compd., Vol. 464, No. 1-2, pp. 33-37.

8 Glowacki, B. A., M. Majoros, M. Vickers, J. E. Evetts, and Y. Shi, (2014), Superconductivity of powder-in-tube MgB 2 wires, Supercond. Sci. Technol., Vol. 14, hal. 193-199.

9 Ranot, M., S. H. Jang, Y. S. Oh, K. P. Shinde, S. H. Kang, and K. C. Chung, (2016), Addition effects of nanoscale $\mathrm{NiO}$ on microstructure and superconducting properties of $\mathrm{MgB}_{2}$, Prog. Supercond. Cryog., Vol. 18, No. 1, hal. 37-40.

10 Novosel, N., Galic, S., Pajic, D., (2012) Enhancement of the critical current density in MgB 2 wires doped with Ni nanoparticles, Supercond. Sci. Technol., Vol. 25, No. 9.

11 Jung, A., Schlachter, S. I., Runtsch, B., (2010) "Influence of $\mathrm{Ni}$ and $\mathrm{Cu}$ contamination on the superconducting properties of $\mathrm{MgB}_{2}$ filaments," Supercond. Sci. Technol., Vol. 23, No. 9. 